\title{
Germinação e crescimento inicial de genótipos de cajueiro anão-precoce em condições de salinidade ${ }^{1}$
}

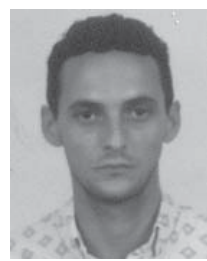

\author{
Paulo T. Carneiro ${ }^{2}$, Pedro D. Fernandes ${ }^{3}$, Hans R. Gheyi ${ }^{4}$ \& Frederico A.L. Soares ${ }^{5}$
}

\begin{abstract}
1 Parte da Dissertação de Mestrado do primeiro autor, apresentada à UFPB
2 Fone: (83) 335-2436. E-mail: ptorrescarneiro@bol.com.br (Foto)

${ }^{3}$ DEAg/CCT/UFCG. CP 10.087, CEP 58109-970, Campina Grande, PB. Fone: (83) 310-1185. E-mail: pdantas@deag.ufpb.br 4 DEAg/CCT/UFCG. CP 10.087, CEP 58109-970, Campina Grande, PB. Fone: (83) 310-1056. E-mail: hans@deag.ufpb.br

${ }^{5}$ DEAg/CCT/UFCG. Fone: (83) 335-4526. E-mail: fredantonio@globalmail.com.br
\end{abstract}

Protocolo $154-7 / 11 / 2001$

\begin{abstract}
Resumo: Foram avaliados, em casa-de-vegetação, os efeitos de quatro níveis de condutividade elétrica da água de irrigação (CEa: 0,$7 ; 1,4 ; 2,1$ e 2,8 $\mathrm{dS} \mathrm{m}^{-1}$, a $25^{\circ} \mathrm{C}$ ) contendo $\mathrm{Na}: \mathrm{Ca}: \mathrm{Mg}$ na proporção equivalente $7: 2: 1$, sobre a germinação e o crescimento inicial, durante 50 dias, de cinco clones de cajueiro anão-precoce (Anacardium occidentale L.): CCP06, CCP09, CCP1001, EMBRAPA50 e EMBRAPA51. O experimento foi conduzido em blocos ao acaso e esquema fatorial $4 \times 5$, com 4 repetições. Avaliaram-se, também, as variáveis de germinação (dias e percentagens de plântulas emergidas) e de crescimento (altura de planta, número de folhas, área foliar e fitomassa de raízes, da parte aérea e total). A maioria das variáveis estudadas foi influenciada pela salinidade da água de irrigação e variou entre clones sem, entretanto, haver efeito interativo desses fatores. Em CEa de 1,48 dS $\mathrm{m}^{-1}$ foi obtida uma produção relativa de $90 \%$ da fitomassa total, podendo este valor ser considerado limite de tolerância à salinidade, para o crescimento inicial do cajueiro anão-precoce. Em geral, os clones EMBRAPA51 e CCP1001 foram os de menor e maior desenvolvimento, respectivamente, em todo o período de estudo.
\end{abstract}

Palavras-chave: condutividade elétrica, fitomassa, Anacardium occidentale L.

\section{Germination and initial growth of precocious dwarf cashew genotypes under saline conditions}

\begin{abstract}
The effects of four levels of electrical conductivity of irrigation water (ECw: $0.7 ; 1.4$; 2.1 and $2.8 \mathrm{dS} \mathrm{m}^{-1}$, at $25^{\circ} \mathrm{C}$ ), containing $\mathrm{Na}: \mathrm{Ca}: \mathrm{Mg}$ in equivalent proportions of 7:2:1, on germination and initial growth stages of five clones of precocious dwarf cashew (Anacardium occidentale L.): CCP06, CCP09, CCP1001, EMBRAPA50 and EMBRAPA51, during the first 50 days were studied in greenhouse. The experiment was carried out in a randomized block design and $4 \times 5$ factorial scheme with 4 replications. The germination (days and percentage of emergence) and growth variables (plant height, number of leaves, leaf area and dry weight of root, shoot and total) were evaluated. The majority of variables were found to be influenced by ECW and clones, however no significant interactive effect was observed for the variables. In the treatment of ECW $1.48 \mathrm{dS} \mathrm{m}^{-1} 90 \%$ of relative total biomass production was obtained; this value may be considered as a threshold tolerance for precocious cashew during the initial growth. In general, the clones EMBRAPA51 and CCP1001 showed the least and the highest growth, respectively, during the study period.
\end{abstract}

Key words: electrical conductivity, biomass, Anacardium occidentale L.

\section{INTRODUÇÃO}

O cultivo do caju constitui-se numa atividade de grande importância econômica e social para o Nordeste brasileiro, não só pela absorção de mão-de-obra mas, também, de forma expressiva, na geração de divisas externas. No Brasil, sua expansão se concentra na região Nordeste, sobretudo nos Estados do Ceará, Rio Grande do Norte e Piauí, os quais produzem anualmente 126 mil toneladas de castanha de caju, proporcionando uma exportação de 28 mil toneladas de amêndoas, atualmente o seu principal produto, gerando divisas anuais ao País, da ordem de 135 milhões de dólares (FNP, 1998). Além da castanha, do cajueiro pode ser obtido também o pedúnculo, cujo potencial de aproveitamento, nas mais diferentes formas, poderá torná-lo outro importante produto de exploração (Ramos et al., 1996).

A maioria dos pomares de cajueiro foi implantada para cultivo em regime de sequeiro, utilizando-se mudas 'pé-franco' 
do cajueiro comum. Esta atividade se baseava na possibilidade da cultura ser explorada sob condições de extrema adversidade hídrica, o que resultava em produtividade baixa. Uma das formas de se reduzir o problema foi a obtenção do cajueiro anãoprecoce, permitindo a adoção de sistemas de plantio adensados com clones melhorados, poda, uso de fertilizantes e controle fitossanitário, possibilitando incremento na produtividade, de até $942 \%$ de castanhas e aproveitamento total do pedúnculo (Ramos et al., 1996). Nesse contexto, cresceram as perspectivas de utilização da irrigação para aumento da produtividade, ampliação do período de colheita e melhoria da qualidade da castanha e do pedúnculo. Vale a pena salientar, entretanto, que o uso inadequado da água em áreas semi-áridas, predominantes no Nordeste brasileiro, tem ocasionado a salinização de solos (Audry \& Suassuna, 1995).

A salinidade dos solos, conforme Coelho (1983) tem-se constituído num dos mais sérios problemas para a agricultura irrigada, em diversas partes do mundo. Em termos globais, um quarto de toda a área irrigada encontra-se seriamente afetada por sais, agravando-se a cada ano (Postel, 1989). No Brasil, são aproximadamente nove milhões de hectares cobrindo sete Estados do Nordeste. Na Bahia está a maior área de solos afetados por sais do País (em torno de $44 \%$ do total), seguida pelo Ceará, com 25,5\% (Pereira, 1983).

Há registros de grande variabilidade de comportamento entre as culturas com relação aos limites de tolerância à salinidade. Genótipos de uma mesma espécie podem responder diferenciadamente à ação da salinidade e o nível de tolerância de um mesmo genótipo pode ser também diferente entre as distintas fases do seu desenvolvimento (Maas, 1986; Maas \& Grattan, 1999). Todavia, a maioria das espécies é relativamente sensível à salinidade e, em geral, as culturas são incapazes de tolerar condições permanentes de estresse salino no solo (Kramer, 1984).

Apesar da reconhecida importância socioeconômica da cajucultura para o Nordeste e da magnitude dos problemas de salinidade na região, poucos trabalhos de pesquisa têm sido desenvolvidos, com o objetivo de investigar os efeitos da irrigação com águas de diferentes qualidades em cajueiro. Em todos os estudos anteriores, as águas foram preparadas com $\mathrm{NaCl}$ e $\mathrm{CaCl}_{2}$ (Santos \& Meireles, 1997; Meireles, 1999) ou apenas com $\mathrm{NaCl}$ (Ferreira et al., 2000) sem qualquer informação envolvendo a presença conjunta dos três principais cátions $(\mathrm{Na}, \mathrm{Ca}, \mathrm{Mg}$ ), predominantes nas águas utilizadas em irrigação no Nordeste (Medeiros, 1992).

O trabalho objetivou estudar os efeitos de diferentes níveis de condutividade elétrica da água de irrigação, com constituição similar à de águas do semi-árido nordestino, sobre a germinação e o crescimento inicial das plantas de cinco genótipos de cajueiro anão-precoce.

\section{MATERIAL E MÉTODOS}

$\mathrm{O}$ experimento foi realizado no período de novembro a dezembro/1999, em casa-de-vegetação do Departamento de Engenharia Agrícola/UFCG, em Campina Grande, PB, situado nas coordenadas geográficas $7^{\circ} 15^{\prime} 18^{\prime \prime}$ de latitude Sul, $35^{\circ} 52^{\prime} 28^{\prime \prime}$ de longitude Oeste do meridiano de Greenwich e altitude de $550 \mathrm{~m}$.
Os tratamentos consistiram de quatro níveis de salinidade (S) expressos em termos de condutividade elétrica da água de irrigação - CEa: $\mathrm{S}_{1}-0,7 ; \mathrm{S}_{2}-1,4 ; \mathrm{S}_{3}-2,1 \mathrm{e} \mathrm{S}_{4}-2,8 \mathrm{dS} \mathrm{m}^{-1}$ (a $\left.25{ }^{\circ} \mathrm{C}\right)$, testados em cinco clones de cajueiro anão-precoce (Anacardium occidentale L.): CCP06 $\left(\mathrm{C}_{1}\right)$, CCP09 $\left(\mathrm{C}_{2}\right)$, EMBRAPA50 $\left(\mathrm{C}_{3}\right)$, EMBRAPA51 $\left(\mathrm{C}_{4}\right)$ e CCP1001 $\left(\mathrm{C}_{5}\right)$. Utilizouse delineamento experimental em blocos casualizados, com quatro repetições, compondo um fatorial $4 \times 5$. A unidade experimental foi formada por cinco vasos (1 planta por vaso) com avaliação até 50 dias após a semeadura (DAS).

As águas de irrigação foram preparadas mediante adição de $\mathrm{NaCl}, \mathrm{CaCl}_{2} .2 \mathrm{H}_{2} \mathrm{O}$ e $\mathrm{MgCl}_{2} .6 \mathrm{H}_{2} \mathrm{O}$, de forma a se obter cada valor da condutividade elétrica (CEa) desejada, mantendo-se uma proporção equivalente de 7:2:1 para $\mathrm{Na}, \mathrm{Ca}$ e $\mathrm{Mg}$, respectivamente. As sementes dos clones (safra 1999) foram fornecidas pela EMBRAPA - Agroindústria Tropical, provenientes do Campo Experimental localizado em Pacajus, CE.

Foram utilizados vasos plásticos com dimensões de $0,25 \mathrm{~m}$ de altura e $0,10 \mathrm{~m}$ de diâmetro, com furos na base para drenagem, preenchidos com substrato composto de um material de solo tipo Podzólico 'franco arenoso', pH 4,54 não salino e não sódico, e húmus de minhoca, na proporção (base em peso) de 29:1; previamente, o substrato foi esterilizado com 'brometo de metila' $\left(150 \mathrm{~mL} \mathrm{~m}^{-3}\right)$.

Antes da semeadura, realizou-se calagem mediante o método de saturação de bases, para elevar a percentagem de saturação para 70\% (Osaki, 1991). Estimou-se a quantidade de carbonato de cálcio pelo referido método e, a partir daí, a equivalência em termos de hidróxido de cálcio, utilizado como corretivo. A dose do produto foi de $0,65 \mathrm{~g} \mathrm{~kg}^{-1}$ de solo, levando-se em consideração o seu grau de pureza (85\%). Juntamente com o corretivo da acidez, incorporou-se fósforo na base de $5,0 \mathrm{~kg}$ de superfosfato simples por metro cúbico do substrato (EMBRAPA, 1993); assim, cada vaso, contendo 2,1 kg de substrato, recebeu 7,66 $\mathrm{g}$ de superfosfato simples, correspondendo a $1,38 \mathrm{~g}$ de $\mathrm{P}_{2} \mathrm{O}_{5}$.

Após o enchimento dos vasos, o substrato foi submetido a três lavagens, para reduzir o seu índice salino: as duas primeiras, com aplicações de 1,0 L de água do sistema de abastecimento local (CEa de $1,16 \mathrm{dS} \mathrm{m}^{-1}$ ) a última, com $0,5 \mathrm{~L}$ de água destilada.

As sementes foram submetidas a choque térmico para acelerar o processo de germinação, ficando submersas em água, inicialmente na temperatura de $40^{\circ} \mathrm{C}$, por um período de $24 \mathrm{~h}$, voltando paulatinamente às condições ambientais. Após o período de pré-embebição, foram devidamente tratadas com fungicida e, em seguida, efetuada a semeadura, colocando-se uma semente por vaso, inserida na posição vertical, com o arilo voltado para cima, a uma profundidade de $3 \mathrm{~cm}$ (EMBRAPA, 1993).

A água foi aplicada em dias alternados e ao final da tarde fornecendo-se, manualmente, $300 \mathrm{~mL}$ por vaso de água do respectivo tratamento salino, visando possibilitar uma drenagem de aproximadamente $20 \%$.

A avaliação do processo germinativo foi feita diariamente, contando-se as sementes germinadas, tendo como critério a emergência do epicótilo na superfície do vaso e registrando-se o número de dias para a semente germinar. Neste trabalho avaliou-se a germinação por um período de 30 dias após a 
semeadura (DAS) cinco a mais do adotado por Santos \& Meireles (1997) e Meireles (1999), também em cajueiro. O prolongamento do período de estudo foi necessário, pelo fato da salinidade normalmente atrasar a embebição de água, pelas sementes e sua germinação.

A avaliação do crescimento inicial das plantas ocorreu aos 50 DAS, através das variáveis: altura de planta (AP), mensurada da inserção dos cotilédones até a base da última folha emitida; número de folhas (NF) considerando-se aquelas com comprimento mínimo de 3,0 cm; área foliar (AF) obtida pelo produto entre o comprimento da folha $(\mathrm{C})$ e sua maior largura (L), corrigida pelo fator de ajuste ' $\mathrm{f}$ ' (Eq. 1): o valor ' $\mathrm{f}$ ' encontrado foi de 0,6544 , obtido por avaliação das plantas de dois blocos, com base na equação supracitada, conhecendose a área real das folhas, através de relação entre discos de área conhecida e peso da matéria seca (Fernandes, 2000); teor de água das folhas (TAF) expresso em percentagem sobre o peso da fitomassa fresca (Eq. 2); fitomassa seca da parte aérea (FSPA), da raiz (FSR) e total (FST) e relação raiz/parte aérea (R/PA) utilizando-se dos respectivos valores de fitomassa $\operatorname{seca}($ Eq. 3):

$$
\begin{gathered}
\mathrm{AF}=(\mathrm{CxL}) \mathrm{f} \\
\mathrm{TAF}=[(\mathrm{PF}-\mathrm{PS}) / \mathrm{PF}] \times 100 \\
\mathrm{R} / \mathrm{PA}=\mathrm{FSR} / \mathrm{FSPA}
\end{gathered}
$$

Os dados obtidos foram avaliados em esquema fatorial, por meio de análise de variância com teste F. Para o fator 'níveis de salinidade da água de irrigação', realizou-se análise de regressão polinomial e, para o fator 'clones', foi aplicado o teste de Tukey $(\mathrm{p}<0,05)$ para comparação das médias, segundo recomendações de Santos et al. (1998). Antes das análises de variância, os dados de área foliar e número de folhas foram transformados em $\sqrt{\mathrm{x}}$, os de fitomassa seca da parte aérea, de raiz e total e relação raiz/parte aérea, em $\sqrt{\mathrm{x}+1}$, e os de teor de água das folhas em arc seno $\sqrt{\mathrm{x}(\%)}$, com base em Ferreira (1996); no entanto, para essas variáveis, a discussão se baseou nos dados originais, visando uma melhor compreensão do efeito dos fatores estudados.

\section{RESULTADOS E DISCUSSÃO}

\section{Germinação}

A percentagem de germinação ( $P G)$ não foi afetada significativamente pela salinidade da água de irrigação; no entanto, ocorreu efeito significativo dos tratamentos salinos $(\mathrm{p}<0,05)$ atrasando o início de germinação (Tabela 1), avaliado pelo número de dias para germinar (NDG). Conforme os estudos de regressão (Figura 1) o aumento da salinidade da água retardou, linearmente, o processo germinativo, independente do genótipo, com incremento relativo (em relação a $\mathrm{S}_{1}: 0,7 \mathrm{dS}$ $\mathrm{m}^{-1}$ ) de 3,89\% para cada incremento unitário de CEa. Santos \& Meireles (1997) trabalhando com dois dos clones também utilizados neste trabalho (CCP06 e CCP1001) verificaram efeitos
Tabela 1. Resumo da Análise de Variância (ANAVA) e médias para percentagem de germinação $(\mathrm{PG})$ e número de dias para

\begin{tabular}{|c|c|c|}
\hline \multirow{2}{*}{ Causa de Variância } & \multicolumn{2}{|c|}{ Variáveis } \\
\hline & PG & NDG \\
\hline & \multicolumn{2}{|c|}{ Teste F } \\
\hline Salinidade (S) & $0,8053 \mathrm{~ns}$ & $3,3210 *$ \\
\hline Reg. Pol. Linear & - & $5,2053 *$ \\
\hline Reg. Pol. Quadricítica & - & $1,0220 \mathrm{~ns}$ \\
\hline Reg. Pol. Cúbica & - & $1,0834 \mathrm{~ns}$ \\
\hline Clones $(\mathrm{C})$ & $10,6100 * *$ & $8,9665 * *$ \\
\hline $\mathrm{S} \times \mathrm{C}$ & $0,5332 \mathrm{~ns}$ & $0,5691 \mathrm{~ns}$ \\
\hline QMResíduo & 306,3158 & 4,1643 \\
\hline \multirow[t]{2}{*}{$\mathrm{CV}(\%)$} & 22,58 & 9,78 \\
\hline & \multicolumn{2}{|c|}{ Médias } \\
\hline Salinidade & $\%$ & dias \\
\hline $\mathrm{S}_{1}\left(0,7 \mathrm{dS} \mathrm{m}^{-1}\right)$ & 74,00 & 20,43 \\
\hline $\mathrm{S}_{2}\left(1,4 \mathrm{dS} \mathrm{m}^{-1}\right)$ & 80,00 & 19,94 \\
\hline $\mathrm{S}_{3}\left(2,1 \mathrm{dS} \mathrm{m}^{-1}\right)$ & 81,00 & 21,23 \\
\hline $\mathrm{S}_{4}\left(2,8 \mathrm{dS} \mathrm{m}^{-1}\right)$ & 75,00 & 21,81 \\
\hline Clones & & \\
\hline $\mathrm{C}_{1}(\mathrm{CCP} 06)$ & $93,75 \mathrm{a}$ & $19,06 \mathrm{a}$ \\
\hline $\mathrm{C}_{2}(\mathrm{CCP} 09)$ & $70,00 \mathrm{~b}$ & $19,87 \mathrm{a}$ \\
\hline $\mathrm{C}_{3}$ (EMBRAPA50) & $61,25 \mathrm{~b}$ & $22,84 \mathrm{c}$ \\
\hline $\mathrm{C}_{4}$ (EMBRAPA51) & $71,25 \mathrm{~b}$ & $21,92 \mathrm{bc}$ \\
\hline $\mathrm{C}_{5}(\mathrm{CCP} 1001)$ & $91,25 \mathrm{a}$ & $20,55 \mathrm{ab}$ \\
\hline $\mathrm{dms}$ & 17,44 & 2,03 \\
\hline
\end{tabular}
germinação (NDG) de cinco clones de cajueiro anão-precoce sob diferentes níveis de salinidade da água de irrigação (CEa)

Reg. Pol. - Regrressão Polinomial

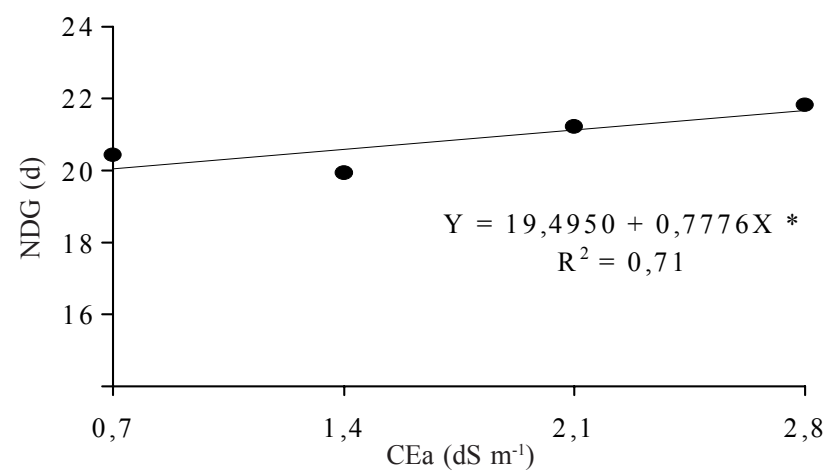

Figura 1. Número médio de dias para germinação (NDG) de clones de cajueiro anão-precoce em relação à condutividade elétrica da água de irrigação $(\mathrm{CEa})$

sobre o percentual de germinação em níveis de condutividade elétrica acima de $1,97 \mathrm{dS} \mathrm{m}^{-1}$, ressaltando-se terem os autores salinizado a água de irrigação $\operatorname{com~} \mathrm{NaCl}$ e $\mathrm{CaCl}_{2}$, na proporção $1: 1$, diferente, portanto, das condições do presente trabalho, em que se teve uma relação 7:2:1 entre $\mathrm{Na}: \mathrm{Ca}: \mathrm{Mg}$. Em outra pesquisa, Meireles (1999) utilizou o clone CCP76 enxertado em CCP06 e CCP1001, estudando os efeitos de águas de irrigação contendo $\mathrm{NaCl}_{\text {e }} \mathrm{CaCl}_{2}$ (proporção 1:1) e registrou, igualmente, prolongamento do período de germinação, além de efeito deletério sobre o percentual de sementes germinadas, quando irrigadas com águas de CEa superior a 2,63 dS m-1.

O retardamento da germinação pode ser resultado da redução do potencial osmótico da solução do solo, causada pelo 
aumento da concentração dos sais solúveis, interferindo negativamente na disponibilidade de água do solo e, por conseguinte, na absorção de água pelas sementes (Rhoades \& Loveday, 1990).

O efeito significativo para o fator 'clones', no tocante ao percentual de germinação e número de dias para germinar (Tabela 1) não está relacionado com a salinidade, pois não houve efeito significativo para a interação $(\mathrm{C} \times \mathrm{S})$ indicando que as diferenças encontradas entre materiais genéticos não dependeram do nível de CEa da água de irrigação.

Os maiores percentuais de sementes germinadas foram obtidos com os clones $\mathrm{C}_{1}$ (CCP06) e $\mathrm{C}_{5}$ (CCP1001) mas sem diferença significativa entre ambos, e os valores mais baixos foram registrados em $\mathrm{C}_{3}$ (EMBRAPA50), $\mathrm{C}_{2}(\mathrm{CCP} 09)$ e $\mathrm{C}_{4}$ (EMBRAPA51). Meireles (1999) também não constatou diferenças significativas entre os clones CCP06 (média de 92,08\%) e CCP1001 (média de 94,79\%) na percentagem de germinação.

As sementes do clone $\mathrm{C}_{1}(\mathrm{CCP} 06)$ germinaram em menor número de dias (média de 19,06 d) diferenciando-se estatisticamente $(\mathrm{p}<0,05)$ de $\mathrm{C}_{3}$ (EMBRAPA50) e $\mathrm{C}_{4}$ (EMBRAPA51) cujas sementes demoraram 22,84 e 21,92 d para germinar, respectivamente. Meireles (1999) ainda obteve variação significativa no número de dias para germinação entre clones; no entanto, contrariamente ao presente trabalho, CCP06 diferiu estatisticamente de CCP1001, demorando mais para germinar (médias de 19,03 e 17,8 d, respectivamente). Vale ser ressaltado que a germinação do cajueiro pode chegar a $25 \mathrm{~d}$ (Cavalcante Jr., 1994, apud Meireles, 1999).

\section{Crescimento e desenvolvimento}

O fator 'salinidade da água de irrigação' afetou $(\mathrm{p}<0,01)$ negativamente o crescimento das plantas em altura (Tabela 2) sendo linear o efeito, segundo os estudos de regressão (Figura 2A) com decréscimo relativo (comparado a $S_{1}$ ) para cada incremento unitário de CEa de 8,49\%. Registrou-se, também, diferença na altura de plantas, entre os clones $(p<0,01)$. Conforme pode ser constatado na Tabela 2, as plantas de $\mathrm{C}_{5}$ (CCP1001) apesar de não diferirem de $\mathrm{C}_{2}$ (CCP09) cresceram mais em altura que os outros clones. Meireles (1999) ao trabalhar com apenas dois dos materiais genéticos, constatou maior crescimento de CCP1001, em relação a CCP06, aos 30 e 60 DAS, fato também verificado neste trabalho. Entretanto, aquele autor obteve efeito significativo para a interação clone x salinidade, aos 60 DAS, sendo a altura das plantas de CCP1001 mais afetada pela salinidade que a do outro clone, a partir de 2,04 $\mathrm{dS} \mathrm{m}^{-1}$. Vale ressaltar ter sido usada, por aquele autor, água salinizada com partes iguais de cloreto de cálcio e cloreto de sódio.

Os efeitos dos fatores 'salinidade da água de irrigação' e 'clones' sobre a altura de planta, ocorreram de forma isolada (Tabela 2) sem haver efeito interativo, devido a altura de planta ter decrescido com o aumento da salinidade, de modo estatisticamente igual nos cinco genótipos.

Já em relação a número de folhas (NF) não foi observada diferença significativa entre clones nem, também, efeito da salinidade da água (Tabela 2). No trabalho conduzido por Meireles (1999) na fase de formação de porta-enxerto com os clones CCP1001 e CCP06, aos 30 e 60 dias após a semeadura, constatou-se redução significativa no número de folhas, em ambos os períodos, quando as plantas foram irrigadas com

Tabela 2. Resumo de ANAVA e médias para altura de planta (AP), número de folhas (NF), área foliar (AF) e teor de água das folhas

(TAF) aos 50 dias após semeadura de cinco clones de cajueiro anão-precoce irrigados com águas de diferentes salinidades

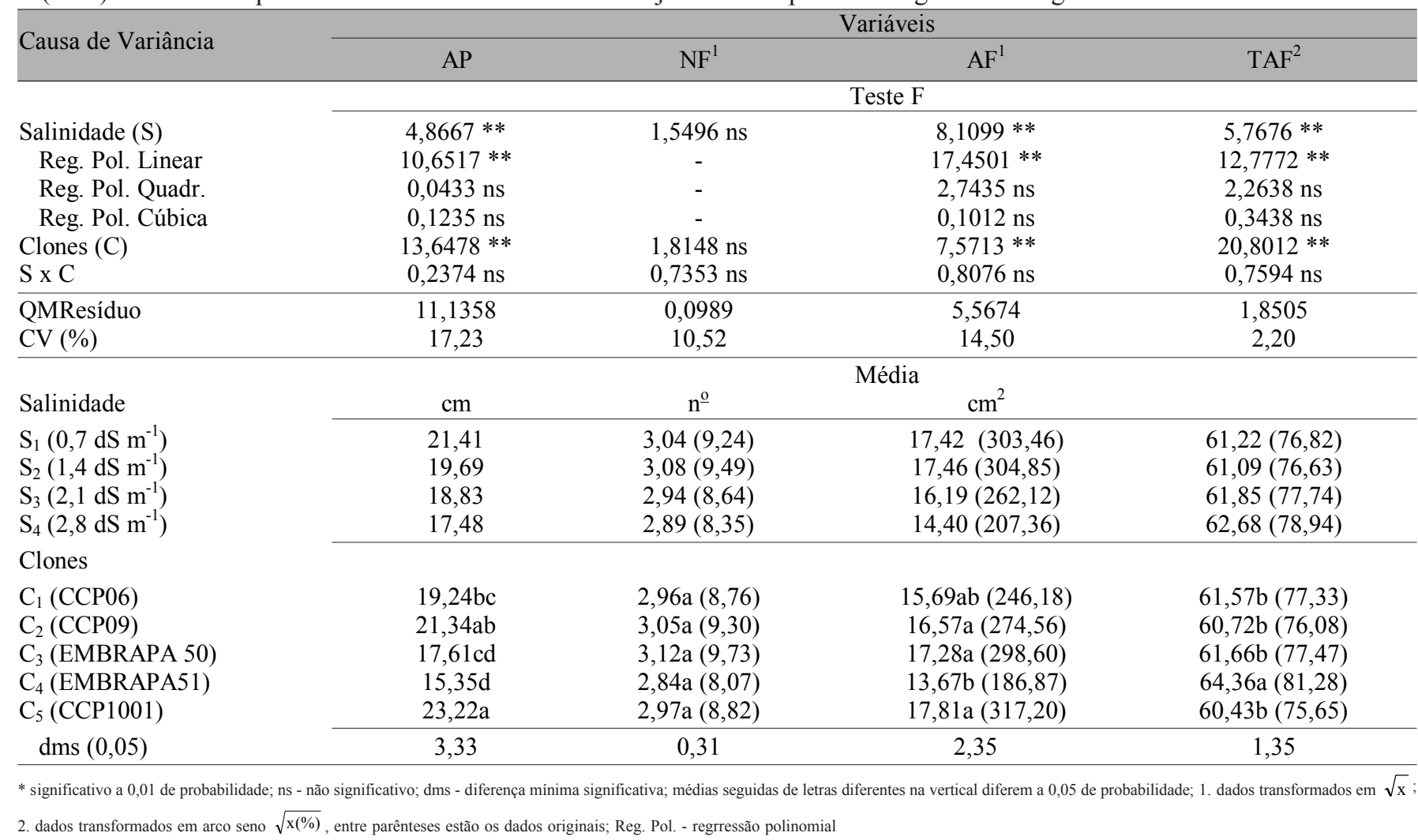


A.

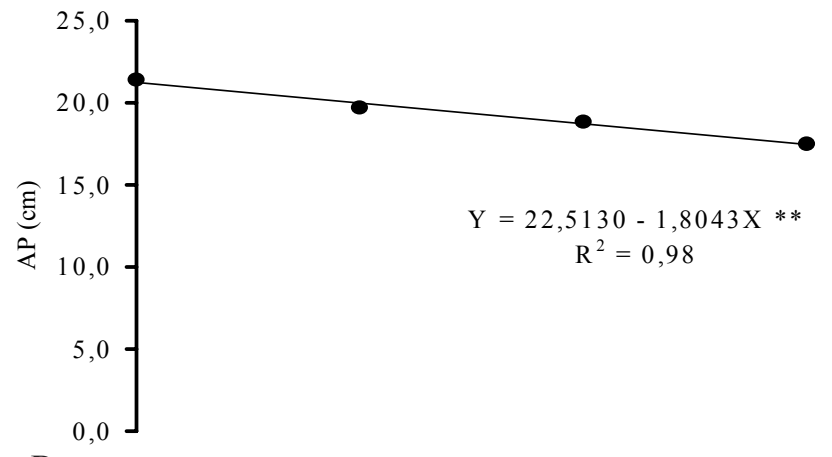

B.

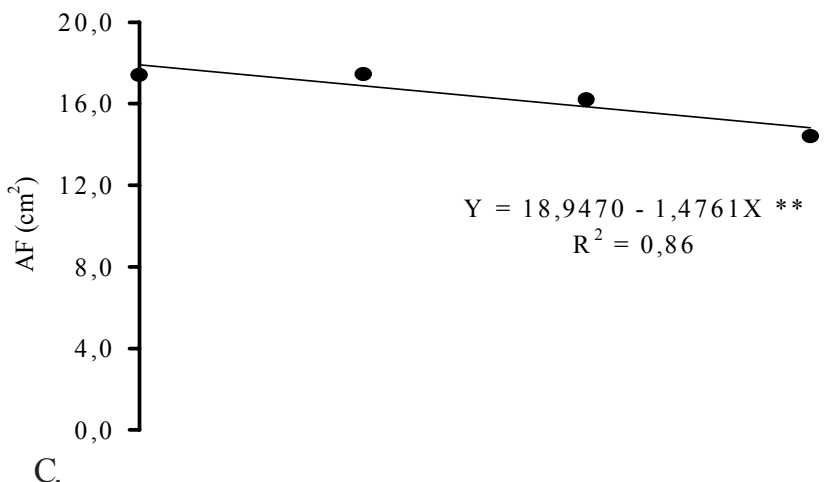

C.

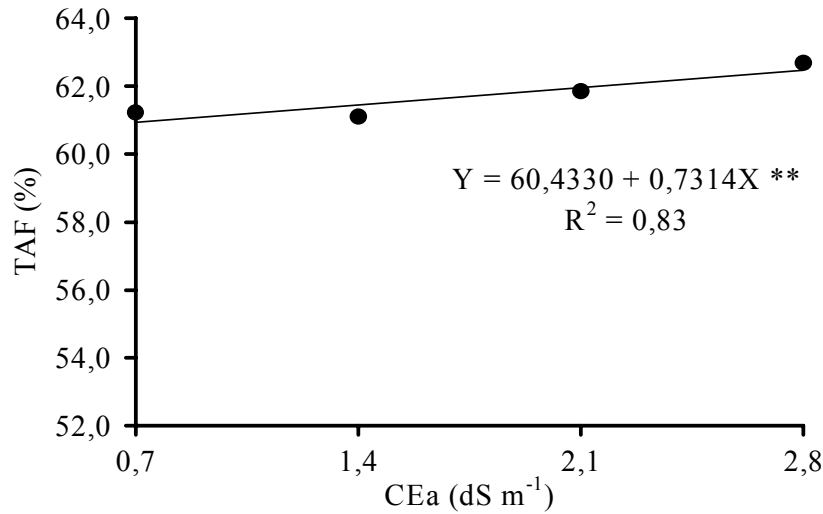

Figura 2. Altura de planta - AP (A), área foliar - AF (B) e teor de água das folhas - TAF (C) aos 50 dias após semeadura de clones de cajueiro anão-precoce, em função da condutividade elétrica da água de irrigação (CEa)

água de condutividade elétrica a partir de $2,04 \mathrm{dS} \mathrm{m}^{-1} \mathrm{sem}$, entretanto, haver diferença significativa entre os clones.

De acordo com a análise de variância (Tabela 2), a área foliar (AF) das plantas foi afetada pela salinidade da água de irrigação e variou entre os clones ( $p<0,01)$, sem entretanto, ser interativo o efeito desses fatores. Pelos estudos de regressão, verifica-se ter a salinidade contribuído linearmente para a redução da área foliar das plantas de todos os genótipos, a nível de 0,01 de probabilidade (Fig. 2B), havendo decréscimo de $14,82 \%$ (relatio a $\mathrm{S}_{1}$ ) por incremento unitário de CEa.

Segundo alguns autores, a deficiência hídrica induzida pelo efeito osmótico, que caracteriza a seca fisiológica, provoca alterações morfológicas e anatômicas nas plantas, a ponto de desbalancear a absorção de água e a taxa de transpiração; dentre as mudanças morfológicas, a redução do tamanho das folhas é a mais expressiva (Maas \& Nieman, 1978; Fageria, 1989; Santos \& Gheyi, 1994). Para Läuchi \& Epstein (1990),
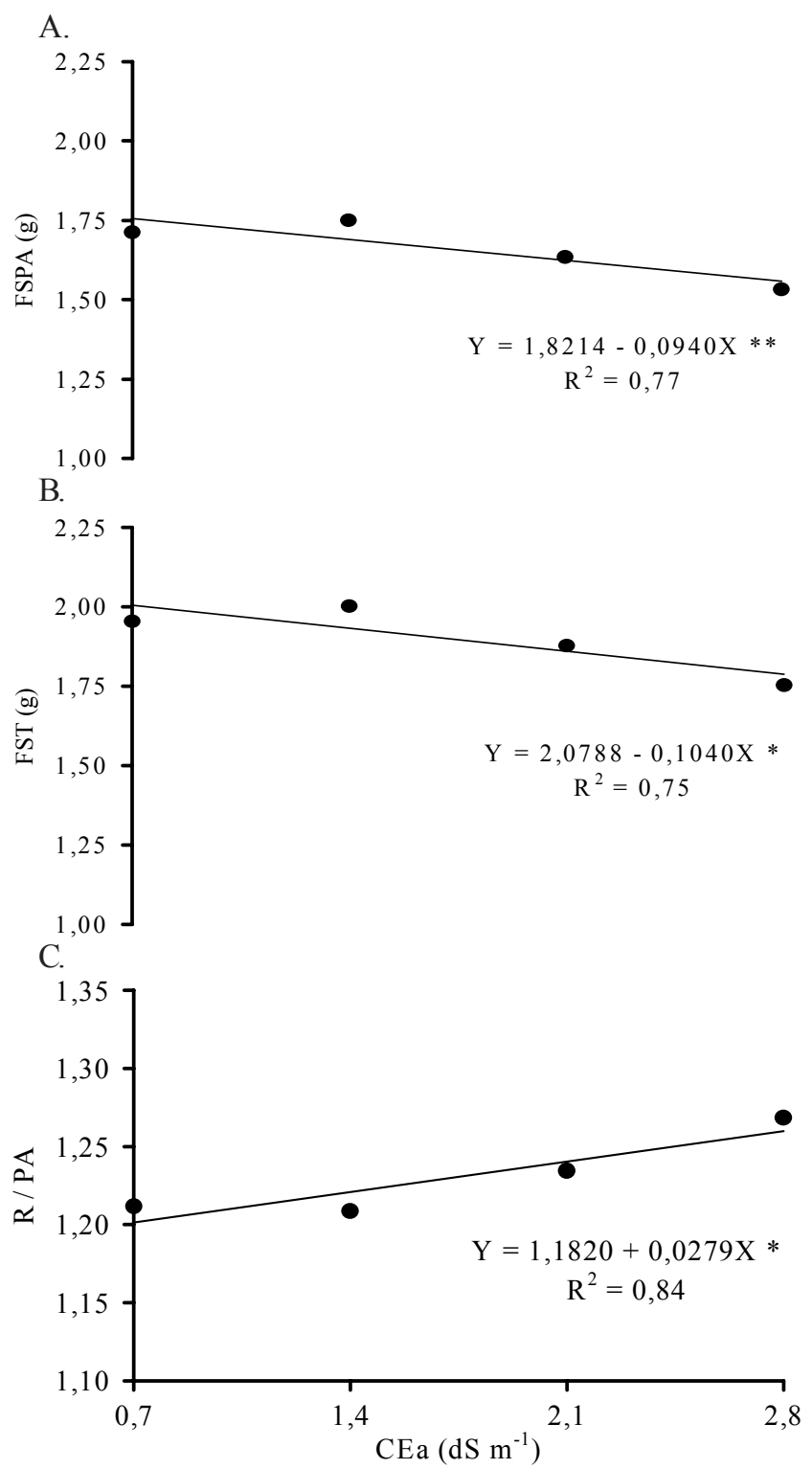

Figura 3. Fitomassa seca da parte aérea - FSPA (A) e total - FST (B) e relação raiz/parte aérea - R/PA (C) aos 50 dias após semeadura de clones de cajueiro anão-precoce, em função da condutividade elétrica da água de irrigação (CEa)

Araújo (1994) e Souza (1995) a redução da área foliar decorre provavelmente, da diminuição do volume de células; afirmam os autores, ainda, que a redução da área foliar se reflete em fotossíntese menor contribuindo, de certo modo, para adaptação da cultura à salinidade.

Dentre os clones, a menor AF foi observada na EMBRAPA51 $\left(\mathrm{C}_{4}\right)$ não se diferenciando estatisticamente de $\mathrm{CCP} 06\left(\mathrm{C}_{1}\right)$. Foi de $41,09 \%$ o decréscimo de $\mathrm{AF}$ ocorrido em $\mathrm{C}_{4}$, em relação a CCP1001 $\left(\mathrm{C}_{5}\right)$, o clone que formou maior superficie foliar. Ferreira et al. (2000) encontraram maior redução no crescimento das folhas de EMBRAPA50 e EMBRAPA51, estudando os efeitos de $\mathrm{NaCl}$ na água de irrigação (CEa $5 \mathrm{dS} \mathrm{m}^{-1}$ ) em dez genótipos de cajueiro, envolvendo o tipo comum e o anão.

\section{Teor de água das folhas}

A salinidade da água de irrigação interferiu significativamente sobre o estado hídrico das plantas, determinado com 
base no teor de água das folhas - TAF (Tabela 2). Os valores aumentaram linearmente $(\mathrm{p}<0,01)$ com os níveis de salinidade (Figura 2C) e aumento relativo (comparado a $\mathrm{S}_{1}$ ) de 1,40\% por unidade de salinidade da água de irrigação. Este fenômeno pode ser resultado do início do processo de ajustamento osmótico, com a planta acumulando íons no vacúolo das células ou sintetizando compostos orgânicos (Lima, 1997) como forma de baixar o potencial hídrico interno e garantir a absorção de água para manter a turgescência das células, porém o aumento da concentração de solutos osmoticamente ativos reduz o potencial osmótico. Nessas condições, a água no interior das células, mesmo em maior proporção, tem o seu estado de energia potencial total diminuído e, em conseqüência, também a sua capacidade de realizar trabalho (Cairo, 1995) refletindo-se em menor crescimento da planta.

Dentre os clones, verifica-se superioridade do genótipo EMBRAPA51 $\left(\mathrm{C}_{4}\right)$, por ter acumulado maior teor de água nas folhas.

Apesar do efeito isolado dos fatores estudados sobre o TAF, estatisticamente significativo (Tabela 2) não foi ele interativo, indicando que o aumento linear do teor de água na folha com o incremento da salinidade ocorreu de maneira similar nos cinco genótipos estudados.

\section{Fitomassa}

A produção de fitomassa da parte aérea (FSPA) dos genótipos foi afetada negativamente $(\mathrm{p}<0,01)$ pela salinidade da água de irrigação (Tabela 3). Os resultados decresceram linearmente (Fig. 3A) com o incremento da $\mathrm{CEa}$, na proporção de $14,81 \%$ para cada unidade de salinidade excedente à água utilizada com menor concentração de sais.
Verificou-se, também, efeito isolado do fator 'clone' em relação à FSPA $(\mathrm{p}<0,01)$; as plantas do clone EMBRAPA51 $\left(\mathrm{C}_{4}\right)$ foram as que acumularam menos matéria seca na parte aérea, apenas $51,40 \%$, em relação à dos demais genótipos, que não diferiram entre si.

Ao contrário da FSPA, a salinidade da água de irrigação não afetou a produção de fitomassa seca de raiz (FSR) mas foram observadas diferenças significativas $(p<0,01)$ entre os clones (Tabela 3). Por não ser significativa a interação C x S, a matéria seca de raízes produzida pelos clones não dependeu dos níveis de salinidade, de maneira similar ao ocorrido para FSPA. Dentre os clones, o que produziu menos matéria seca de raiz foi novamente o EMBRAPA51, da ordem de $54 \%$ em relação aos outros.

A fitomassa seca total (FST) foi, também, afetada pela salinidade da água de irrigação e pelo fator clones ambos a nível de 0,01 de probabilidade, sem efeito significativo da interação, sugerindo não haver diferenças de FST entre os genótipos estudados em função da salinidade.

A produção de fitomassa seca total (FST) foi, também, reduzida linearmente com o aumento da condutividade elétrica da água (Fig. 3B). O decréscimo, em relação ao tratamento com água de menor salinidade $\left(\mathrm{S}_{1}\right)$ foi de $12,89 \%$ para cada incremento unitário de salinidade. De acordo com Ayers \& Westcot (1999) como critério para escolha de uma cultura, quando se levam em conta problemas de salinidade, pode ser aceita uma diminuição no rendimento potencial de até $10 \%$, isto é, a salinidade máxima aceitável é aquela que permite produzir rendimento relativo mínimo de $90 \%$. Pela equação obtida, na condutividade elétrica da água de irrigação de

Tabela 3. Resumo de ANAVA e médias para fitomassa seca da parte aérea (FSPA), de raiz (FSR) e total (FST) e relação raiz/parte aérea (R/PA) aos 50 dias após a semeadura de cinco clones de cajueiro anão-precoce, irrigados com água de diferentes salinidades

\begin{tabular}{|c|c|c|c|c|c|c|c|c|}
\hline \multirow{2}{*}{ Causa de Variância } & \multicolumn{8}{|c|}{ Variáveis } \\
\hline & \multicolumn{2}{|c|}{ FSPA $^{1}$} & \multicolumn{2}{|c|}{$\mathrm{FSR}^{1}$} & \multicolumn{2}{|c|}{$\mathrm{FST}^{1}$} & \multicolumn{2}{|c|}{$\mathrm{R} / \mathrm{PA}^{1}$} \\
\hline & \multicolumn{8}{|c|}{ Teste F } \\
\hline Salinidade (S) & \multicolumn{2}{|c|}{$6,5659 * *$} & \multicolumn{2}{|c|}{$2,3798 \mathrm{~ns}$} & \multicolumn{2}{|c|}{$5,3196 * *$} & \multicolumn{2}{|c|}{$4,6871 * *$} \\
\hline Reg. Pol, Linear & \multicolumn{2}{|c|}{$14,7825 * *$} & \multicolumn{2}{|c|}{-} & \multicolumn{2}{|c|}{$10,4240 * *$} & \multicolumn{2}{|c|}{$8,7876 * *$} \\
\hline Reg. Pol. Quadr. & \multicolumn{2}{|c|}{$3,3430 \mathrm{~ns}$} & \multicolumn{2}{|c|}{-} & \multicolumn{2}{|c|}{$2,9697 \mathrm{~ns}$} & \multicolumn{2}{|c|}{$1,5726 \mathrm{~ns}$} \\
\hline Reg. Pol. Cúbica & \multicolumn{2}{|c|}{$0,9786 \mathrm{~ns}$} & \multicolumn{2}{|c|}{-} & \multicolumn{2}{|c|}{$0,5853 \mathrm{~ns}$} & \multicolumn{2}{|c|}{$0,1074 \mathrm{~ns}$} \\
\hline QM Resíduo & \multicolumn{2}{|c|}{0,0279} & \multicolumn{2}{|c|}{0,0093} & & & & \\
\hline $\mathrm{CV}(\%)$ & 10 & & & & & & & \\
\hline & & & & & & & & \\
\hline Salinidade & & ? & & & & & & \\
\hline $\mathrm{S}_{1}\left(0,7 \mathrm{dS} \mathrm{m}^{-1}\right)$ & 1,7121 & $(1,9313)$ & 1,3705 & $(0,8783)$ & 1,9540 & $(2,8181)$ & 1,2118 & $(0,4685)$ \\
\hline $\mathrm{C}_{1}(\mathrm{CCP} 06)$ & $1,6423 \mathrm{a}$ & $(1,6971)$ & $1,3443 \mathrm{~b}$ & $(0,8071)$ & $1,8703 \mathrm{a}$ & $(2,4980)$ & $1,2138 \mathrm{a}$ & $(0,4733)$ \\
\hline $\mathrm{C}_{2}(\mathrm{CCP} 09)$ & $1,6775 \mathrm{a}$ & $(1,8140)$ & $1,3845 \mathrm{ab}$ & $(0,9168)$ & $1,9293 \mathrm{a}$ & $(2,7222)$ & $1,2304 \mathrm{a}$ & $(0,5139)$ \\
\hline $\mathrm{C}_{3}$ (EMBRAPA50) & $1,7248 \mathrm{a}$ & $(1,9749)$ & $1,3799 \mathrm{ab}$ & $(0,9041)$ & $1,9689 \mathrm{a}$ & $(2,8766)$ & $1,2239 \mathrm{a}$ & $(0,4979)$ \\
\hline $\mathrm{C}_{4}$ (EMBRAPA51) & $1,4248 \mathrm{~b}$ & $(1,0301)$ & $1,2288 \mathrm{c}$ & $(0,5099)$ & $1,5908 \mathrm{~b}$ & $(1,5306)$ & $1,2446 \mathrm{a}$ & $(0,5490)$ \\
\hline $\mathrm{C}_{5}(\mathrm{CCP} 1001)$ & $1,7662 \mathrm{a}$ & $(2,1195)$ & $1,4550 \mathrm{a}$ & $(1,1170)$ & $2,0564 \mathrm{a}$ & $(3,2288)$ & $1,2361 \mathrm{a}$ & $(0,5279)$ \\
\hline $\operatorname{dms}(0,05)$ & 0,1665 & & 0,0960 & & 0,2076 & & 0,0551 & \\
\hline
\end{tabular}

** - Significativo a $0,01 \mathrm{e}^{*}$ - significativo a 0,05 de probabilidade; ns: não significativo; dms - diferença mínima significativa; médias seguidas de letras diferentes na vertical diferem a 0,05 de probabilidade Dados transformados em $\sqrt{\mathrm{x}+1}$; entre parênteses estão as médias dos dados originais 
$1,48 \mathrm{dS} \mathrm{m}^{-1}$ ocorreu redução de $10 \%$ no rendimento inicial do cajueiro anão-precoce, expresso pela produção total de matéria seca podendo, então, ser considerado valor limite de salinidade para produção de mudas, até 50 dias após semeadura.

Analisando-se o efeito isolado de 'clones' (Tabela 3) observa-se que o genótipo EMBRAPA51 $\left(\mathrm{C}_{4}\right)$ foi significativamente menos vigoroso, produzindo menos matéria seca total (FST) que os demais clones $(\mathrm{p}<0,05)$; em relação a $\mathrm{C}_{5}$ (CCP1001) aquele clone produziu 52,60\% menos fitomassa seca total.

\section{Relação raiz/parte aérea}

A relação raiz/parte aérea $(\mathrm{R} / \mathrm{PA})$ foi afetada $(\mathrm{p}<0,01)$ somente pelo fator 'salinidade da água de irrigação' (Tabela 3) sendo linear e crescente o efeito (Fig. 3C) ocorrendo incremento, relativamente a $\mathrm{S}_{1}$, de $15,58 \%$ para cada aumento unitário de salinidade, segundo os estudos de regressão.

$\mathrm{O}$ aumento da relação R/PA, com o incremento dos níveis de salinidade (Fig. 3C) se deu em função da maior redução na biomassa da parte aérea. A redução da fitomassa da parte aérea, entre as plantas irrigadas com água de 0,7 e $2,8 \mathrm{dS} \mathrm{m}^{-1}$, foi de $31,10 \%$, enquanto nas raízes o decréscimo entre os mesmos tratamentos foi de apenas 17,81\%. Através desta comparação, constata-se que o crescimento da parte aérea foi mais prejudicado pela salinidade que o do sistema radicular, resultando numa relação maior R/PA. Esses dados estão em acordo com observações de Fageria (1989), Poljakoff-Mayber \& Lerner (1993) e Azevedo Neto \& Tabosa (2000) podendo ser um indicativo de adaptação morfo-fisiológica da cultura à salinidade; com a redução do potencial hídrico do solo, as plantas aumentam a capacidade de absorção de água e diminuem a taxa de transpiração (Maas \& Nieman, 1978; Fageria, 1989; Shalhevet et al., 1995)

\section{CONCLUSÕES}

1. A salinidade da água de irrigação não interfere quantitativamente no processo germinativo do cajueiro, mas prolonga o período de germinação.

2. O incremento da salinidade da água inibe o crescimento da planta em altura, área foliar, produção de fitomassa seca da parte aérea e total, mas aumenta o teor de água das folhas.

3. O efeito da salinidade até $50 \mathrm{~d}$ após a semeadura é mais intenso sobre a parte aérea que sobre o sistema radicular, resultando em aumento na relação raiz/parte aérea.

4. O cajueiro é mais tolerante à salinidade durante a germinação que na fase de desenvolvimento inicial.

5. O limite de salinidade da água de irrigação para o crescimento inicial do cajueiro anão-precoce é de $1,48 \mathrm{dS} \mathrm{m}^{-1}$, para uma perda máxima de produção de fitomassa de $10 \%$.

6. Os efeitos da salinidade independem dos materiais genéticos estudados; o clone EMBRAPA51 é o que tem os menores índices de crescimento e o clone CCP1001 os maiores valores.

\section{LITERATURA CITADA}

Araújo, C.A.S. Avaliação de feijoeiros quanto a tolerância à salinidade em solução nutritiva. Viçosa: UFV, 1994. 87p. Dissertação Mestrado
Ayers, R.S.; Westcot, D.W. A qualidade da água na agricultura. Campina Grande: UFPB, 1999. 153p. FAO. Estudos de Irrigação e Drenagem, 29.

Audry, P.; Suassuna, J. A salinidade das águas disponíveis para a pequena irrigação no sertão do Nordeste: caracterização, variação sazonal, limitação de uso. Recife: $\mathrm{CNPq}$, 1995. 128p.

Azevedo Neto, A.D. de; Tabosa, J.N. Estresse salino em plântulas de milho. Parte I: análise do crescimento. Revista Brasileira de Engenharia Agrícola e Ambiental, Campina Grande, v.4, n.2, p.159-164, 2000.

Cairo, P.A.R. Curso básico de relações hídricas de plantas. Vitória da Conquista: UESB, 1995.32p.

Coelho, M.A. Aspecto da dinâmica da água em solos sódicos e salino-sódicos. Ciência Agronômica, Fortaleza, v.14, n.1-2,p.61-68, 1983.

EMBRAPA. Empresa Brasileira de Pesquisa Agropecuária. Aspectos agroeconômicos sobre a cultura do cajueiro. Fortaleza: Centro Nacional de Pesquisa de Agroindústria Tropical, 1993. 124p.

Fageria, N.K. Solos tropicais e aspectos fisiológicos das culturas. Brasília: EMBRAPA/DPU, 1989. 425p. EMBRAPACNPAF. Documento, 18

Fernandes, P.D. Análise de crescimento e desenvolvimento vegetal. Campina Grande: Departamento de Engenharia Agrícola, UFPB, 2000, 22p.

Ferreira, O.S.; Matos, N.N.; Meneses Júnior, J.; Barros, L. de M.; Lima Júnior, A.; Silveira, J.A.G. da. Avaliação inicial da tolerância ao estresse salino em materiais de cajueiro (Anacardium occidentale L.) através de índices de crescimento. In: Congresso Brasileiro de Fruticultura, 16, 2000, Fortaleza, Anais... Fortaleza: SBF, 2000. CD-Rom

Ferreira, P.V. Estatística experimental aplicada à agronomia. 2. ed. Maceió: UFAL/EDUFAL/FUNDEPES, 1996. 604p.

FNP, Consultoria \& Comércio. Agrianual 98: anuário estatístico de agricultura brasileira. São Paulo, 1998. 481p. cap.: Caju.

Kramer, D. Cytological aspects of salt tolerance in higher plants. In: Staples, C.; Toenniessen, G.H. (eds.). Salinity tolerance in plants: Strategies for crop improvement. New York: John Wiley \& Sons. 1984. p.3-15.

Läuchi, A.; Epstein, E. Plant responses to saline and sodic conditions. In: Tanji, K.K. (ed.). Agricultural salinity assessment and management. New York: ASCE, 1990. cap. 6,p.113-137.

Lima, L.A. Efeito de sais no solo e na planta. In: Gheyi, H.R.; Queiroz, J.E.; Medeiros, J.M. (eds.). Manejo e controle da salinidade na agricultura. Campina Grande: UFPB/SBEA, 1997. p. 113-136.

Maas, E.V. Salt tolerance of plants. Applied Agricultural Research, New York, v.1, p.12-36, 1986.

Maas, E.V.; Grattan, S.R. Crop yields as affected by salinity. In: Skaggs, R.W.; van Schilfgaarde, J. (eds) Agricultural drainage. Madison: ASA, CSSA, SSSA. 1999. p.55-108. Agronomy Monograph, 38

Maas, E.V.; Nieman, R.H. Physiology of tolerant plants to salinity. In: Jung, G.A. (ed.). Crop tolerance to sub-optimal land conditions. Madison: American Society Agronomy 1978. cap. 1.p.277-299. Special Publication, 32 
Medeiros, J.F. Qualidade de água de irrigação e evolução da salinidade nas propriedades assistidas pelo 'GAT' nos estados de RN, PB e CE. Campina Grande: UFPB, 1992. 173p. Dissertação Mestrado

Meireles, A.C.M. Salinidade da água de irrigação e desenvolvimento de mudas de cajueiro anão-precoce (Anacardium occidentale L.). Fortaleza: UFC, 1999. 60p. Dissertação Mestrado

Osaki, F. Calagem e adubação. 2. ed. Campinas: Instituto Brasileiro de Ensino Agrícola, 1991. 503p.

Pereira, J.R. Solos salinos sódicos. In: Reunião de Fertilidade do Solo, 15, 1983, Campinas. Anais... Campinas: Sociedade Brasileira de Ciências do Solo, 1983. p.127-143.

Poljakoff-Mayber, A.; Lerner, H.R. Plants in saline environments. In: Pessarakli, M. (ed). Handbook of plant and crop stress. New York: Marcel Dekker. 1993. cap.4, p.65-125.

Postel, S. Water for agriculture: Facing the limits. Washington: Worldwatch Institute. 1989. 54p. Worldwatch Paper, 93

Ramos, A.D.; Bleicher, E.; Freire, F. das C. de O.; Cardoso, J.E.; Parente, J.I.G.; Barros, L. de M.; Crisóstomo, L.A.; Frota, P.C.E.; Corrêa, M.P.F.; Paula Pessoa, P.F.A. de; Melo, Q.M.S.; Oliveira, V.H. de. A cultura do caju. Brasília: SPI, 1996. 96p. Coleção Plantar, 34
Rhoades, J.D.; Loveday, J. Salinity in irrigated agriculture. In: Stewart, D.R.; Nielsen, D.R. (eds.). Irrigation of agricultural crops. Madison: ASA, CSSA, SSSA, 1990. p.1089-1142. Agronomy, 30

Santos, F.J. de S.; Meireles, A.C.M. Efeito da qualidade da água sobre a germinação em viveiro de dois clones de cajueiro anão-precoce (Anacardium occidentale L.). In: Congresso Brasileiro de Engenharia Agrícola, 26, 1997, Campina Grande. Anais... Campina Grande: SBEA, 1997. CD-Rom

Santos, J.G.R. dos; Gheyi, H.R. Efeitos da salinidade da água na composição da folha da bananeira e nas características do solo. Pesquisa Agropecuária Brasileira, Brasília, v.29, n.2, p.247-253, 1994.

Santos, J.W. dos; Moreira, J. de A.N.; Beltrão, N.E. de Macedo. Avaliação do emprego dos testes de comparação de médias na revista Pesquisa Agropecuária Brasileira (PAB) de 1980 a 1994. Pesquisa Agropecuária Brasileira, Brasília, v.33, n.3, p.225-230, 1998 .

Shalhevet, J.; Huck, M.G.; Schroeder, B.P. Root and shoot growth responses to salinity in maize and soybean. Agronomy Journal, Madison, v.87, p.512-516, 1995.

Souza, M.R. Comportamento do feijoeiro (Phaseolus vulgaris L. Cv. Eriparza) submetido a diferentes níveis de salinidade da água de irrigação. Lavras: UFLA, 1995. 94p. Dissertação Mestrado 